\title{
SÍNTESE DE POLIESTIRENO SULFONADO PARA APLICAÇÕES NO TRATAMENTO DE ÁGUA PRODUZIDO A PARTIR DE COPOS E BANDEJAS DESCARTADAS DE POLIESTIRENO
}

\author{
Guimes Rodrigues Filho, Rosana M. N. de Assunção*, Flavia C. A. Marques, Natália G. Corrente e Carla da Silva \\ Meireles \\ Instituto de Química, Universidade Federal de Uberlândia, Av. João Naves de Avila, 2121, 38400-902 Uberlândia - MG, Brasil \\ Daniel A. Cerqueira \\ Departamento de Química, Universidade de Coimbra, 3004-535 Coimbra, Portugal / Instituto de Química, Universidade Federal \\ de Uberlândia, Av. João Naves de Avila, 2121, 38400-902 Uberlândia - MG, Brasil
}

Alan S. Landim

Departamento de Municipal de Água e Esgoto de Uberlândia, Uberlândia - MG, Brasil

Recebido em 16/11/07; aceito em 30/6/08; publicado na web em 10/11/08

\begin{abstract}
SYNTHESIS OF POLY(STYRENE SULFONATE) FROM DISCARDED POLYSTYRENE CUPS AND EXPANDED TRAYS FOR APPLICATION ON WATER TREATMENT. In the present paper, the use of poly(styrene sulfonate) (PSS), produced from discarded polystyrene materials through heterogeneous and homogeneous processes, was investigated. The use of PSS for water treatment, using a kaolin suspension as wastewater model, reduced water turbidity for all the employed materials when compared to the blank analysis, without PSS. The most efficient polyelectrolyte was PSS cups obtained by homogeneous route. The same behavior was observed for real system. The homogeneous PSS cups showed a balance between a moderate molecular weight and high anionic character that improved flocks formation and water removal turbidity.
\end{abstract}

Keywords: polystyrene post-consume; poly(styrene sulfonate); water treatment.

\section{INTRODUÇÃO}

A reciclagem de materiais tornou-se um campo merecedor de pesquisa, desenvolvimento e aplicação de recursos, uma vez que existe um interesse ambiental e econômico na retirada de materiais descartados do meio ambiente. Neste sentido, a busca por rotas viáveis para o aproveitamento de materiais, seja em sua forma química original ou através de sua transformação química, vem sendo estudada visando encontrar mercado para seu emprego.

Os polímeros são os materiais que têm a maior contribuição para o impacto ambiental, pois vêm gradativamente substituindo materiais como vidros e metais devido sua baixa densidade e propriedades físicas e químicas versáteis. O poliestireno faz parte desta grande família de polímeros. Possui boas propriedades mecânicas e isolantes sendo empregado em vários setores como materiais descartáveis (copos, pratos, bandejas, etc), proteção para equipamentos eletrônicos e espumas para embalagens e proteção. Devido ao elevado consumo de poliestireno, o destino final observado para estes materiais são aterros e lixões, uma vez que este raramente é reciclado em sua forma original. Isto ocorre porque o processo de reciclagem não compensa economicamente, devido ao baixo preço da resina virgem.

Um caminho alternativo para o aproveitamento do poliestireno é modificá-lo quimicamente produzindo um novo material. A sulfonação do poliestireno, por exemplo, conduz à produção de um polieletrólito que pode ser empregado como aditivo para argamassas e concretos ${ }^{1}$ e agente floculante no processo de tratamento de água e esgoto. ${ }^{2-4} \mathrm{O}$ tipo de aplicação depende do caráter eletrolítico do polímero, da massa molecular, do $\mathrm{pH}$ do meio, entre outras propriedades. Assim, devido ao elevado caráter eletrolítico do poliestireno sulfonado em certas situações ele atuará melhor como um agente dispersante,

\footnotetext{
*e-mail: rosanassuncao@gmail.com
}

uma vez que em certas concentrações ocorrerá geração de forças repulsivas devido às cargas negativas do PSS (Poliestireno sulfonado) adsorvido sobre as partículas do meio. Este aspecto é importante em processos de dispersão como o uso deste material como aditivo, mas indesejável no uso deste como agente floculante. Desta forma, o uso deste material no tratamento de água deve ser realizado na etapa de neutralização das cargas das partículas e, portanto, as condições do meio e a concentração do polieletrólito são fundamentais durante o processo. A neutralização das cargas é um processo fundamental durante o tratamento de água, pois permite a remoção de partículas suspensas, metais pesados e substâncias húmicas..$^{5-7}$

Para modificar os materiais a condição de sulfonação pode ser modificada através de dois métodos: sulfonação homogênea e heterogênea. A escolha das condições para sulfonação é feita considerando 3 fatores: nível de sulfonação, tipo de isômero formado e rendimento da reação. ${ }^{8} \mathrm{O}$ método mais freqüentemente empregado em meio homogêneo é a sulfonação do PS solubilizado em dicloroetano e o emprego do acetilsulfato, produzido pela reação do anidrido acético com o ácido sulfúrico concentrado, como agente sulfonante. ${ }^{8}$ Poliestireno sulfonado com um elevado grau de sulfonação também pode ser obtido através da rota heterogênea. Neste caso, pode-se empregar o PS em pó adicionado em ácido sulfúrico concentrado (agente sulfonante) e sulfato de prata como catalisador. ${ }^{2,8}$ A vantagem do uso do acetilsulfato como agente sulfonante é o emprego de baixas concentrações de ácido sulfúrico em comparação ao emprego direto do ácido sulfúrico como agente sulfonante. No entanto, a síntese em meio heterogêneo tem como vantagem o não emprego de solventes durante o processo, o que facilita a separação dos produtos finais.

Considerando os aspectos apresentados acima, neste trabalho foram avaliados poliestirenos sulfonados (PSS) produzidos a partir de duas fontes distintas de materiais descartados (copos e bandejas de PS expandido). A síntese dos polímeros foi realizada a partir de 
duas rotas: homogênea e heterogênea. Os polieletrólitos foram caracterizados através da espectroscopia na região do infravermelho e a partir da viscosimetria das soluções. O desempenho dos materiais no tratamento de água foi avaliado em dois sistemas: uma suspensão de kaolin usada como modelo de água a ser tratada, e esgoto bruto da estação de tratamento de esgoto (ETE-Aclimação, município de Uberlândia MG). A análise foi realizada com base em medidas de turbidez, considerando a água antes e após o tratamento com o coagulante primário (sulfato de alumínio ou cloreto férrico) e o polieletrólito (poliestireno sulfonado, PSS).

\section{PARTE EXPERIMENTAL}

\section{Preparação do poliestireno sulfonado}

O poliestireno sulfonado foi produzido a partir de 2 métodos: rota heterogênea, onde o poliestireno reagiu com ácido sulfúrico concentrado $(97 \%)$ usado como agente sulfonante junto com sulfato de prata $\left(\mathrm{Ag}_{2} \mathrm{SO}_{4}\right)$ usado como catalisador conforme o descrito por Assunção et al. ${ }^{1} \mathrm{e}$, rota homogênea, na qual o poliestireno previamente dissolvido em diclorometano foi sulfonado com a espécie reativa acetilsulfato, produzida pela reação do anidrido acético com ácido sulfúrico. ${ }^{3}$ Para produção dos derivados sulfonados foram usados copos e bandejas expandidas de poliestireno pós-consumo.

\section{Determinação da viscosidade intrínseca das soluções}

A massa molecular viscosimétrica dos polímeros foi obtida a partir dos resultados da medida da viscosidade intrínseca das soluções dos polímeros sem modificação e sulfonados. As medidas foram realizadas usando um viscosímetro de Ostwald em um banho termostatizado a $25^{\circ} \mathrm{C}$. Para polímeros sem carga como o poliestireno antes da modificação, a viscosidade reduzida $\left(\eta_{\mathrm{sp}} / \mathrm{c}\right)$ é uma função da concentração das soluções. Para sistemas que se comportam idealmente, esta relação é diretamente proporcional. ${ }^{9}$ Neste caso, a viscosidade intrínseca pode ser determinada a partir da Equação de Huggins (1) e a massa molecular viscosimétrica a partir da relação de Mark-Houwink-Sakurada (2).

$\left(\eta_{\mathrm{sp}} / \mathrm{c}\right)=[\eta]+\mathrm{K}_{\mathrm{H}}[\eta]^{2} \cdot \mathrm{c}$

onde $\left(\eta_{\mathrm{sp}} / \mathrm{c}\right)$ é a viscosidade reduzida $\left(\eta_{\mathrm{sp}}\right.$, viscosidade específica e c, concentração), [ $\eta$ ] é a viscosidade intrínseca, $K_{H}$, constante de Huggins.

$[\eta]=K \cdot\left(M_{v}\right)^{\mathrm{a}}$

onde $\mathrm{K}$ e a são constantes relacionadas à interação polímero solvente em uma determinada temperatura e $\mathrm{M}_{\mathrm{v}}$ é a massa molecular viscosimétrica.

Para polieletrólitos como o PSS, entretanto, a viscosidade apresenta um comportamento diferente. Observa-se o "efeito do polieletrólito", no qual a viscosidade intrínseca aumenta exponencialmente com a diminuição da concentração das soluções. ${ }^{10}$ Para modificar este efeito, a viscosidade do polieletrólito foi estudada na presença de um excesso de sais iônicos de baixa massa molecular. Neste caso, as interações entre os grupos polares na cadeia carbônica são suprimidas e o polieletrólito comporta-se como um polímero neutro. Neste estudo foi utilizado como sistema solvente para o PSS uma solução aquosa de $\mathrm{NaCl}$ 0,52 $\mathrm{mol} \mathrm{L}^{-1} .{ }^{11} \mathrm{O}$ uso deste solvente permite-nos determinar a viscosidade intrínseca das soluções usando a Equação 1 e a massa molecular usando a Equação 2.

\section{Ensaios de tratamento de água (suspensão Kaolin) e esgoto.}

A água usada para avaliar a eficiência do PSS foi uma suspensão de kaolin produzida na proporção de kaolin/água 1,0/96,0\% (m/m). $\mathrm{O}$ processo foi avaliado através da medida da turbidez do sobrenadante após o processo de coagulação/ floculação. Foi utilizado para comparação dos resultados um floculante comercial N3100 ${ }^{\circledR}$ (polímero neutro, baseado em poliacrilamida de alta massa molecular de acordo com dados fornecidos pelo fabricante) empregado na estação de tratamento de água do Departamento Municipal de Água e Esgoto de Uberlândia - MG. A primeira etapa do processo foi realizada com o emprego de um coagulante primário, sulfato de alumínio, $\mathrm{Al}_{2}\left(\mathrm{SO}_{4}\right)_{3}$.

A suspensão de kaolin foi adicionada a provetas graduadas de $100 \mathrm{~mL}$ e os ensaios foram realizados com a adição de $\mathrm{Al}_{2}\left(\mathrm{SO}_{4}\right)_{3}$, PSS copo e N3100 conforme detalhado na Tabela 1.

As mesmas condições experimentais foram usadas no teste com o PSS bandejas. Entretanto, devido às características dos polímeros o teste com PSS bandeja foi realizado usando concentrações inferiores. As medidas de turbidez foram realizadas após 10 min de sedimentação em um turbidímetro Tecnopon TB-1000.

\section{Tratamento do esgoto recolhido da estação de tratamento} Aclimação - DMAE

Este teste foi realizado usando uma adaptação dos ensaios de coagulação/ floculação usados no tratamento de água em um artigo anterior. ${ }^{4}$ As medidas de turbidez foram realizadas após a decantação e flotação dos resíduos na água de esgoto devido à fermentação natural deste nos frascos de Jar test. Em um frasco do Jar test foram adicionados $1 \mathrm{~L}$ de esgoto e $100 \mathrm{mg} \mathrm{L}^{-1}$ de uma solução aquosa de cloreto férrico. Os polieletrólitos foram adicionados aos frascos e um frasco foi mantido como branco (sem polieletrólito). A dose ideal de polieletrólito foi $1 \mathrm{mg} \mathrm{L}^{-1}$, dose já empregada na rotina da estação de tratamento. Os materiais em cada frasco foram agitados a $100 \mathrm{rpm}$ por $1 \mathrm{~min}$ e após, por $20 \mathrm{rpm}$ por $5 \mathrm{~min}$. As misturas foram decantadas por 15 min e, em seguida, a água intermediária entre o lodo flotado e o decantado foi recolhida e submetida a medidas de $\mathrm{pH}$ e turbidez. As medidas de turbidez foram realizadas em um turbidímetro Hach $2100 \mathrm{P}$ e de $\mathrm{pH}$ em um pHmetro Orion 310.

Tabela 1. Arranjo experimental para medidas de turbidez

\begin{tabular}{lcccccc}
\hline \multirow{2}{*}{ Adições } & \multicolumn{5}{c}{ Frasco de teste } \\
& branco & 2 & 3 & 4 & 5 & 6 \\
\hline $\begin{array}{l}\text { Suspensão de } \\
\text { kaolin }\end{array}$ & $\mathrm{X}$ & $\mathrm{X}$ & $\mathrm{X}$ & $\mathrm{X}$ & $\mathrm{X}$ & $\mathrm{X}$ \\
$\mathrm{Al}_{2}\left(\mathrm{SO}_{4}\right)_{3}$ & $\mathrm{X}$ & $\mathrm{X}$ & $\mathrm{X}$ & $\mathrm{X}$ & $\mathrm{X}$ & $\mathrm{X}$ \\
$\begin{array}{l}\text { PSScopo 20 } \\
\text { ppm hom* }\end{array}$ & & $\mathrm{X}$ & & & & \\
$\begin{array}{l}\text { PSScopo } 80 \\
\text { ppm hom }\end{array}$ & & & $\mathrm{X}$ & & & \\
$\begin{array}{l}\text { PSSbandeja } 20 \\
\text { ppm hom }\end{array}$ & & & & & \\
$\begin{array}{l}\text { PSSbandeja } 40 \\
\text { ppm hom }\end{array}$ & & & & & \\
N3100 & & & & $\mathrm{X}$ & \\
\hline
\end{tabular}

* Polieletrólitos foram produzidos pela rota homogênea. As mesmas condições experimentais foram usadas para os polieletrólitos produzidos pela rota heterogênea. 


\section{RESULTADOS E DISCUSSÃO}

O poliestireno sulfonado produzido a partir das rotas homogênea e heterogênea usando como matéria-prima copos plásticos de PS pósconsumo apresenta-se como gel marrom no meio reacional. Ao ser precipitado a partir de uma solução aquosa com elevada concentração de cloreto de sódio forma um pó marrom que pode ser facilmente separado por filtração. O mesmo não ocorre com o poliestireno sulfonado produzido a partir de bandejas de alimentos. Após a reação, forma-se um gel branco extremamente inchado devido à elevada absorção de água. Este aspecto não é modificado durante a etapa de precipitação, a partir de soluções aquosas com elevada concentração de cloreto de sódio ainda era produzido um gel difícil de separar. A elevada solubilidade dos dois polímeros em água, no entanto, é o indício significativo da modificação química sofrida durante a reação de sulfonação, o que pode ser observado nos espectros na região do infravermelho apresentados na Figura 1.

As principais modificações observadas são: o aparecimento de uma banda intensa em aproximadamente $3500 \mathrm{~cm}^{-1}$, devido ao caráter ácido do poliestireno sulfonado e, aparecimento de duas bandas em 1046 e $1178 \mathrm{~cm}^{-1}$, que são evidências da sulfonação, pois são atribuídas ao estiramento simétrico e assimétrico do grupo $-\mathrm{SO}_{2}-\mathrm{O}^{-}{ }^{-12}$ Todos os polieletrólitos produzidos neste trabalho apresentam o mesmo padrão mostrado na Figura 1.

Polímeros são bons agentes auxiliares de coagulação/flotação durante o tratamento de água. No caso de polímeros com elevado caráter aniônico existe a necessidade do emprego inicial do coagulante primário na etapa de neutralização, uma vez que as partículas suspensas na água têm caráter aniônico devido à adsorção de íons
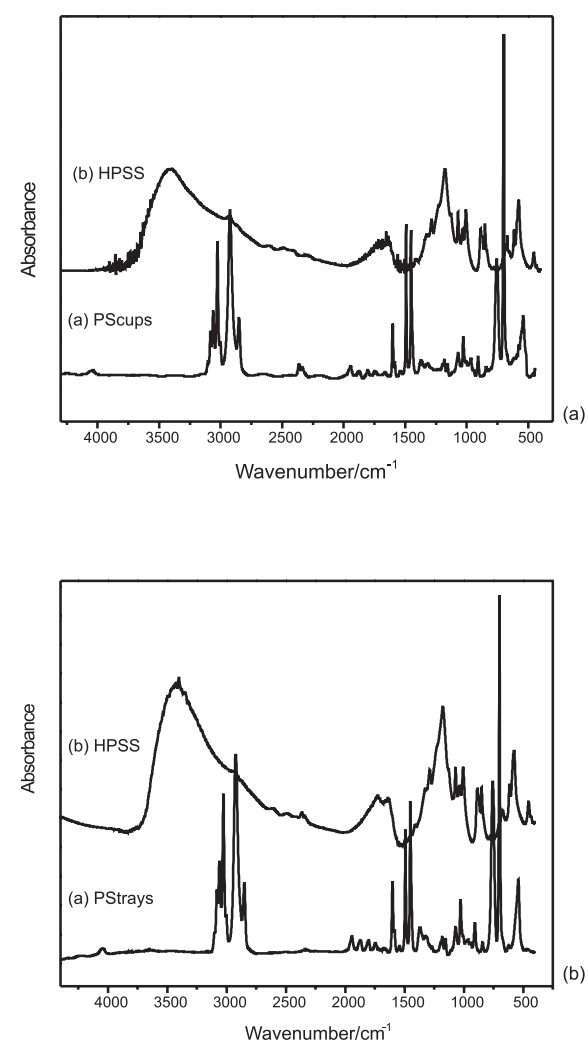

Figura 1. Espectros na região do infravermelho para o poliestireno de copos descartados (PS copo) e poliestireno sulfonado de copos (PSS copos) (A) e poliestireno expandido de bandejas de alimentos ( $P S$ bandeja) e poliestireno sulfonado das bandejas (PSS bandejas) (B) hidroxila. Neste caso, mantendo a rotina da estação de tratamento de água foi usado o sulfato de alumínio. As cargas positivas resultantes da adsorção dos íons alumínio são então neutralizadas pelo polieletrólito, levando à formação de flocos maiores que decantam mais rapidamente. $\mathrm{O}$ mecanismo envolvido no processo está relacionado à adsorção de partículas nos sítios adequados do polímero e/ou aprisionamento de pequenos coágulos ou flocos devido ao tamanho da cadeia polimérica. Esses mecanismos dependem da natureza dos sítios na cadeia e da massa molecular dos polímeros. A modificação química sofrida pelo poliestireno após a sulfonação pode ser observada de forma contundente devido ao aspecto apresentado pelos espectros na região do infravermelho, solubilidade em água e cor do produto. Em trabalho anterior, ${ }^{1}$ observou-se que o PSS produzido pela rota heterogênea atinge de 58 a $63 \%$ de grupos sulfônicos. Este fato indica o elevado caráter aniônico deste polieletrólito.

A Tabela 2 apresenta os valores de massa molecular viscosimétrica para os polímeros antes e depois da sulfonação. Os resultados foram avaliados de forma qualitativa, uma vez que a determinação depende das concentrações das soluções e o poliestireno sulfonado obtido a partir das bandejas em forma um gel, o que dificulta a determinação da concentração exata do polímero.

Considerando os materiais de partida, o PS obtido de copos plásticos descartados (PS copo) apresenta menor massa molecular média que o PS expandido (PS bandeja) obtido de bandejas de alimentos. Esta diferença aparece nos resultados de massa molecular viscosimétrica para os polímeros sulfonados. Ambos os polímeros apresentam massa molecular elevada devido à incorporação dos grupos sulfônicos. Entretanto, o fato relevante apresentado na Tabela 2 é a diferença entre as massas molares obtidas para os polímeros produzidos pelas rotas homogênea e heterogênea independente das fontes de materiais empregados neste trabalho; observa-se um decréscimo na massa molar dos polieletrólitos produzidos a partir da rota heterogênea. Este fato pode ser explicado considerando as condições de síntese dos materiais. Na rota heterogênea a elevada quantidade de ácido sulfúrico empregado em comparação ao que é empregado na rota homogênea leva à diminuição do tamanho da cadeia e degradação do polímero mais rapidamente e, conseqüentemente, a uma diminuição na massa molar dos polieletrólitos, como observado na Tabela 2. Observa-se também que os polieletrólitos produzidos a partir das bandejas de poliestireno possuem massa molecular mais elevada, o que está de acordo com a massa molar mais elevada observada para o poliestireno das bandejas de alimento em comparação ao poliestireno dos copos plásticos.

Os resultados da aplicação do poliestireno sulfonado no tratamento de água (suspensão kaolin/água) são apresentados na Tabela 3 (A) (PSS copo) e (B) (PSS bandeja).

Os resultados apresentados na Tabela 3 (A) mostram um decréscimo na turbidez da água em relação ao branco em todos os ensaios realizados com os polieletrólitos. O principal mecanismo associado à ação do poliestireno sulfonado ocorre devido à adsorção de partículas após o primeiro estágio de neutralização com o sulfato de alumínio. A presença dos íons alumínio melhora a adsorção das partículas nos sítios iônicos da cadeia polimérica devido aos grupos

Tabela 2. Valores de massa molecular média dos polímeros obtidas a partir de medidas viscosimétrica

\begin{tabular}{lcccc}
\hline Polímeros sem modificar & \multicolumn{3}{c}{ Polímeros sulfonados } \\
\hline PS & $\mathrm{M}_{\mathrm{v}} / \mathrm{g} \mathrm{mol}^{-1}$ & PSS & $\begin{array}{c}\mathrm{M}_{\mathrm{v}} / \mathrm{g} \mathrm{mol}^{-1} \\
\text { (hom) }\end{array}$ & $\begin{array}{c}\mathrm{M}_{\mathrm{v}} / \mathrm{g} \mathrm{mol}^{-1} \\
\text { (het) }\end{array}$ \\
Copos & 104000 & Copos & 237788 & 147853 \\
bandejas & 129824 & Bandejas & 302724 & 228846 \\
\hline
\end{tabular}


Tabela 3. Avaliação da eficiência de coagulação - floculação do poliestireno sulfonado produzido a partir de copos (A) e bandejas (B) descartáveis

\begin{tabular}{|c|c|c|c|}
\hline \multicolumn{2}{|c|}{ (A) Poliestireno copos } & \multicolumn{2}{|c|}{ (B) Poliestireno bandejas } \\
\hline Polímeros & Turbidez/ NTU & Polímeros & Turbidez / NTU \\
\hline Branco & 664 & Branco & 654 \\
\hline $\begin{array}{l}\text { PSS hom } \\
20 \text { ppm }\end{array}$ & 592 & $\begin{array}{l}\text { PSS hom } \\
20 \text { ppm }\end{array}$ & 589 \\
\hline $\begin{array}{l}\text { PSS het } \\
20 \mathrm{ppm}\end{array}$ & 602 & $\begin{array}{l}\text { PSS het } \\
20 \mathrm{ppm}\end{array}$ & 605 \\
\hline $\begin{array}{l}\text { PSS hom } \\
80 \text { ppm }\end{array}$ & 417 & $\begin{array}{l}\text { PSS hom } \\
40 \text { ppm }\end{array}$ & 605 \\
\hline $\begin{array}{l}\text { PSS het } \\
80 \text { ppm }\end{array}$ & 562 & $\begin{array}{l}\text { PSS het } \\
40 \mathrm{ppm}\end{array}$ & 620 \\
\hline N3100 & 594 & N3100 & 593 \\
\hline
\end{tabular}

sulfônicos. O melhor resultado observado quanto à remoção de turbidez da água ocorreu com o uso do poliestireno sulfonado de copos descartáveis produzido pela rota homogênea. Este efeito é maior com o aumento da concentração de PSS copo para 80 ppm. Neste caso, o desempenho do PSS copo é ainda superior ao polímero comercial, N3100. A eficiência na remoção de turbidez com o PSS copo atinge $37 \%$, bastante superior aos $11,0 \%$ obtidos com o uso do polímero comercial N3100.

As partículas que estão suspensas na água de tratamento são inicialmente neutralizadas com os íons $\mathrm{Al}^{3+}$. Essas partículas são atraídas fortemente pelos grupos sulfônicos presentes na cadeia polimérica. Essas interações de natureza eletrostática entre as partículas suspensas originais, o sulfato de alumínio e, por último, a interação entre os sítios carregados do polieletrólito com as partículas tratadas com o coagulante primário favorecem a coagulação, floculação e com isto a diminuição da turbidez da água.

A principal diferença entre os polieletrólitos produzidos pelas rotas homogênea e heterogênea é a massa molecular viscosimétrica média. Embora o mecanismo principal proposto para a ação do PSS no tratamento de água seja atribuído à ação de forças eletrostáticas entre as partículas e os sítios iônicos na cadeia polimérica, outro aspecto pode estar envolvido relacionado à massa molecular dos polímeros, levando a uma ação conjunta entre o efeito eletrostático e o tamanho da cadeia polimérica que "abraça" as partículas formando flocos maiores que decantam mais rapidamente. ${ }^{7}$ As diferenças encontradas na Tabela 3(A) podem ser explicadas com base na competição entre estes dois processos.

A mesma metodologia foi empregada para avaliar o comportamento do PSS produzido a partir de bandejas descartadas (Tabela 3(B)). O único parâmetro modificado foi a dosagem de PSS bandeja usada, uma vez que para o mesmo efeito observado com o PSS copo menor dosagem de PSS bandeja (20 ppm) foi necessária. Nesta condição, o desempenho do PSS bandeja preparado pela rota homogênea é similar ao observado para o polímero comercial, N3100. O emprego de concentrações superiores de PSS bandeja (40 ppm) levou a uma inversão de comportamento com um aumento da turbidez da água quando comparado com o teste feito com $20 \mathrm{ppm}$ de polieletrólito. O aumento na turbidez pode ser explicado devido a um efeito de repulsão eletrostática quando se aumenta a concentração do polímero. Como resultado, ao invés de melhorar a coagulação, este efeito favorece a dispersão das partículas. Neste caso, a elevada massa molecular do polímero aumenta a contribuição de grupos aniônicos na cadeia polimérica; este efeito de concentração leva um aumento de forças eletrostáticas repulsivas e torna predominante o mecanismo por forças eletrostáticas.

Estes polieletrólitos foram avaliados no tratamento de esgoto e os resultados estão resumidos na Tabela 4.

O PSS copo produzido a partir da rota homogênea (Tabela 4 (A)) apresentou o melhor desempenho quanto à remoção de turbidez da água quando comparado ao branco com o uso apenas do coagulante primário e ao desempenho do polímero comercial N3100. Os polímeros produzidos pela rota heterogênea mostraram baixa eficiência em comparação ao branco (Tabela 4 (B)). Os resultados obtidos em um sistema real, esgoto, corroboraram aqueles encontrados usando uma suspensão de kaolin como modelo para água de tratamento. Comparações entre os polímeros obtidos pelas rotas homogênea e heterogênea mostram que o melhor desempenho do sistema é dependente do balanço entre o caráter iônico do polieletrólito e sua massa molecular. Pelos resultados apresentados o PSS de copos descartados produzido a partir da rota homogênea parece ter o balanço adequado entre um elevado caráter iônico e moderada massa molecular, o que sugere que o principal mecanismo atuando para estes polímeros envolva forças eletrostáticas.

Tabela 4. Turbidez final da água de esgoto tratada com os polieletrólitos produzidos pela rota homogênea (A) e rota heterogênea (B)

Parâmetros para o tratamento ${ }^{\text {a }}$ de esgoto (A)

Polímeros (rota homogênea)

\begin{tabular}{lcccc} 
Parâmetros para o tratamento & PSS Band. & PSS copos & 100 & 100 \\
\hline Concentração do coagulante** $(\mathrm{ppm})$ & 100 & 100 & 1 & 1 \\
Concentração polieletrólito $(\mathrm{ppm})$ & 0 & 29,6 & 27,3 & 28,9 \\
Turbidez (NTU) & 37,7 & 6,23 & 6,24 & 6,30 \\
pH de coagulação & 6,18 & 1000 \\
\hline
\end{tabular}

a Turbidez inicial da água do esgoto $=58,3$ NTU e $\mathrm{pH}=6,56 * *$ Cloreto férrico

\begin{tabular}{lcccc}
\hline Parâmetros para o tratamento & \multicolumn{2}{c}{$\begin{array}{c}\text { Polímero (rota heterogênea) } \\
\text { PSS band. }\end{array}$} & PSS copos & Comercial \\
\hline Concentração do coagulante** (ppm) & & 100 & 100 & 100 \\
Concentração polieletrólito (ppm) & 100 & 1 & 1 & 1 \\
Turbidez (NTU) & 0 & 15,5 & 15,0 & 6,24 \\
pH de coagulação & 16,1 & 6,23 & 6,30 & 15,2 \\
\hline
\end{tabular}

b Turbidez inicial da água do esgoto $=42,3 \mathrm{NTU}$ e $\mathrm{pH}=7,03 * *$ Cloreto férrico 


\section{CONCLUSÃO}

O emprego de duas rotas de sulfonação, homogênea e heterogênea, tornou possível produzir poliestireno sulfonado a partir de dois materiais pós-consumo: copos e bandejas de alimentos. Os materiais originais apresentam diferentes massas moleculares o que se observa também para os produtos sulfonados. Os polieletrólitos foram testados em suspensões de kaolin onde o PSS copos apresenta melhores resultados, devido ao elevado caráter iônico do polímero que favorece o mecanismo de coagulação/floculação devido a um balanço entre a adsorção de partículas carregadas e ao "abraço" destas partículas pela cadeia polimérica. Os resultados mostraram que a massa molecular, o caráter iônico e a concentração do polímero devem ser considerados para se obter condições de bom desempenho no tratamento de água.

\section{AGRADECIMENTOS}

À CAPES pelo programa PROAP e por tornar disponível o 'Portal de periódicos'. N. G. Corrente agradece à FAPEMIG pelo apoio financeiro.

\section{REFERÊNCIAS}

1. Assunção, R. M. N.; Royer, B.; Oliveira, J. S.; Rodrigues-Filho, G.; Motta, L. A. C.; J. Appl. Polym. Sci. 2005, 96, 1534.

2. Bajdur, W.; Pajaczkowska, J.; Makarucha, B.; Sulkowska, A.; Sulkowski, W. W.; Eur. Polym. J. 2002, 38, 299.

3. Inagaki, Y.; Kuromiya, M.; Noguchi, T.; Watanabe, H.; Langmuir 1999, 15, 4174.

4. Landim, A. S.; Maldonado, A. C. D.; Rodrigues-Filho, G.; Assunção, R. M. N.; 7ํㅡ Congresso Brasileiro de Polímeros, Belo Horizonte, Brasil, 2003.

5. Hilal, N.; Al-Abri, M.; Moran, A.; Al-Hinai, H.; Desalination 2008, 220 , 85.

6. Chang, Q.; Wang, G.; Chem. Eng. Sci. 2007, 62, 4636.

7. Petzold, G.; Mende, M.; Lunkwitz, K.; Schwarz, S.; Buchhammer, H-M.; Colloids Surf., A 2003, 218, 47.

8. Kucera, F.; Jancar, J.; Polym. Eng. Sci. 1988, 38, 783.

9. Sperling, L. H.; Introduction to Physical Polymer Science, Wiley: New York, 1995.

10. Garcia, R.; Gomez, C. M.; Porcar, I.; Figueruelo, J. E.; Campos, A.; Eur. Polym. J. 1997, 33, 1723

11. Aovalik, G.; Ozkan, A.; Polymer 1986, 27, 1277.

12. Smith, B.; Infrared Spectral Interpretation - A Systematic Approach, CRC Press: New York, 1998 